\title{
Marine epibiosis
}

\section{Reduced fouling on Polysyncraton lacazei (Didemnidae, Tunicata) and Proposal of an antifouling potential index}

\author{
Martin Wahl $^{1}$ and Francoise Lafargue ${ }^{2}$ \\ ${ }^{1}$ Zoologisches Institut der Universität Kiel, D-2300 Kiel, Federal Republic of Germany \\ ${ }^{2}$ Lab. Arago, F-66650 Banyuis/mer, France
}

Received October 10,1989/Accepted October 17, 1989

\begin{abstract}
Summary. Polysyncraton lacazei is a colonial tunicate (family didemnidae) living in the NW-mediterranean rocky sublitoral. A thorough scanning of numerous colonies revealed that in spite of an apparently heavy local fouling pressure only one fouling species - a kamptozoan - is encountered with some regularity on Polysyncraton. We try to define the epibiotic situation of sessile marine organisms as composed of four epibiotic parameters: longevity or exposure time (A), epibiont load (E), colonizer pool (CP) and fouling-period (FP). Subsequently, these factors are combined to propose an "Antifouling Potential" index: $A F P=(1-E / C P) \times A /$ $(\mathrm{FP}+\mathrm{A})$. This index is intended to permit evaluating the relative antifouling defense potency to be expected in a given organism in a given epibiotic situation and to compare different cases of epibiosis and fouling.
\end{abstract}

Key words: Epibiosis - Polysyncraton lacazei - Ascidian - Epibiotic parameters - Antifouling potential index

In the marine environment any exposed, non-defended, longlived substratum eventually gets colonized by sessile organisms such as bacteria, diatoms, protozoans, algae and invertebrates. In sharp contrast, the surfaces of numerous sessile marine organisms remain remarkably free of epibionts, a fact that in many cases may be due to underlying antifouling defense adaptations. A whole panoply of possible defense mechanisms may be used singly or combined: mechanical, physical, chemical and extrinsic defenses (Wahl 1989).

Four parameters characterize what we will term the epibiotic situation of a species. Two of these are specific for the species investigated: its exposure time (A), which may be identical to longevity, and its average epibiont load (E). The other two are of more environmental na-

Offprint requests to: $\mathrm{M}$. Wahl ture: the local pool of potential colonizers (CP) and the fouling period (FP).

The influence of other factors, such as small scale biotic environment, size and physiological stage of the organism etc, should be largely leveled down when a large number of specimens of diverse provenience (spatially and seasonally) are examined. Once measured or estimated, A, CP, E and FP will help calculate the antifouling potential index AFP (see conclusion). This index is intended to serve a double purpose:

first, permit comparison from an epibiotic point of view of organisms with different biology and from divers habitats,

second, forecast the potency of antifouling defenses to be expected in a given organism as deduceable from its epibiotic situation.

In the following we will first examine the parameters longevity and epibiont load for a colonial tunicate of the family Didemnidae: Polysyncraton lacazei. We will then discuss the environmental parameters describing an epibiotic situation and propose a new antifouling potential index.

\begin{abstract}
Material
The ascidian colonies used for monitoring (SCUBA), in - situ investigation (SCUBA) or epibiont screening (laboratory) lived abundantly in the rocky infralitoral zone near Banyuls/mer, France $\left(42^{\circ} 29^{\prime} \mathrm{N}, 03^{\circ} 08^{\prime} \mathrm{E}\right)$. The Banyuls bight is situated at the far western end of the Lion Gulf in the northwestern mediterranean. Waters usually are rather turbid and nutrient rich (in part due to the effluents of the far-off Rhône river), leading to a conspicuous predominance of filter feeders (sponges, gorgonians, ascidians ...) in the local sessile fauna.
\end{abstract}

\section{Methods}

Colony monitoring

In the course of a 4 yr survey 16 medium sized $(5-10 \mathrm{~cm}$ diameter), healthy looking colonies of the upper infralitoral zone $(0-5 \mathrm{~m})$ were 
marked by fixing a $15 \times 15 \mathrm{~cm}$, flat, cm-graded aluminium frame to the rock, with the chosen colony at its center. Depending on the accessibility of the location (depth, exposure, distance from lab), the different colonies were surveyed by SCUBA diving weekly to monthly. Divisions, fusions, growth, shrinking of colonies were monitored by placing a transparent, slightly roughened plexiglass plate on the frame and tracing the contours of the colonies with a soft pencil. Condition of colonies, activity state, macroepibionts, injuries etc. were noted parallely. Only the age-related data of this survey will be analyzed in this paper.

\section{Epibionts}

In this study we checked nearly one thousand colonies from six locations around Banyuls/mer $(0-20 \mathrm{~m})$ through 26 months.

Potential epibionts on mediterranean ascidians range in size from about $0,5 \mu \mathrm{m}$ (some bacteria) to well over $1 \mathrm{~cm}$ (c.g. see Monniot 1961). For a complete screening of this wide size range several methods have to be combined:

-Visual: In the field, marked colonies were examined regularly visually and by macrophotography $(1: 1)$.

- Optical screening: Once to twice monthly about 20 freshly collected colonies were scrutinized through a Wild binocular $(\times 60-\times$ 500 ) for the presence of epibionts, activity state, reproductive cycle, etc. When there was doubt about the presence or absence of smaller epibionts, such as cyanobacteria, part of the colony cuticula was exised and examined microscopically.

- SEM : Approximately every three months several colonies, randomly chosen, were scanned for the presence of epibiotic microorganisms (Hitachi S-520). Preparation of specimens:

1. Soft, but extensive rinsing of colony surface with $0,2 \mu \mathrm{m}$ filtered seawater (rinsing pressure ca. $10 \mathrm{~cm}$ water column).

2. Anaesthesia to avoid contraction during fixation: slow $\left(1^{\circ} \mathrm{C} /\right.$ 3 min) cooling of specimen in buffer $\left(0,16 \mathrm{M} \mathrm{NaH}_{2} \mathrm{PO}_{4}\right.$, filtered seawater, neutralized at $\mathrm{pH} 7.4-7.6)$ down to $0^{\circ} \mathrm{C}$. Then addition of a few menthol cristals and a spatula tip of MS222 per liter.

3. When colonies cease to react to slight mechanical stimulus, fixation (15-20 h) by addition of glutaraldehyde (final concentration $3 \%$ ).

4. Extensive rinsing in buffer $(3 \times 20 \mathrm{~min})$.

5. Post-fixation in $1 \% \mathrm{OsO}_{4}$ in buffer $(1-2 \mathrm{~h})$.

6. Rinsing in buffer, progressive transfer in distilled water

7. Dehydration in acetone series $(10 \%$ steps, 3 times $100 \%, 15-$ $30 \mathrm{~min}$ per step according to specimen volume).

8. Critical point drying.

9. Sputtering.

-Microbiological swabbing: Repeatedly, living colonies were examined by this method as a control for the SEM-screening for microepibionts.

1. Rinsing of the colony surface as described.

2. Soft swabbing of a 1 or $2 \mathrm{~cm}^{2}$ area (at least $1 \mathrm{~cm}$ off the colony border) with a sterile, cotton-tipped Pasteur pipette. Care should be taken not to hurt the delicate outer surface of the colony (iiberation of strong acid!)

3. Cotton-tipped end of pipette is broken off within a glass vessel containing $50 \mathrm{ml}$ of sterile seawater.

4. Prolonged, vigorous shaking (vortexing) to remove a maximum of bacteria from the cotton.

5. Log-dilution of the suspension.

6. Culturing of different concentrations on solid medium ( $5 \mathrm{~g}$ peptone, $0.1 \mathrm{~g}$ ferrous phosphate, $15 \mathrm{~g}$ agar agar, $250 \mathrm{ml}$ distilled water, $750 \mathrm{ml}$ seawater). Incubation in the dark at $20^{\circ} \mathrm{C}$, counting of growing colonies after 3-6 days.

Parallel controls: Swabbing of a sterilized glass surface or processing of unused, autoclaved pipette cotton tip.

In this study we have agreed to consider as "regular" epibionts only those with a presence of $>10 \%$ on the screened colonies.
We insist that the choice of this threshold was entirely intuitive. Further experience will certainly help shift this value to an ecologically confirmed position (probably somewhere between $1 \%$ and $15 \%)$.

\section{Results and discussion}

\section{a) Longevity and exposure time of Polysyncraton lacazei colonies}

In this monitoring, the number of clonemates derived from the initial colony frequently changed due to numerous divisions and fusions. For the calculation of survival

a
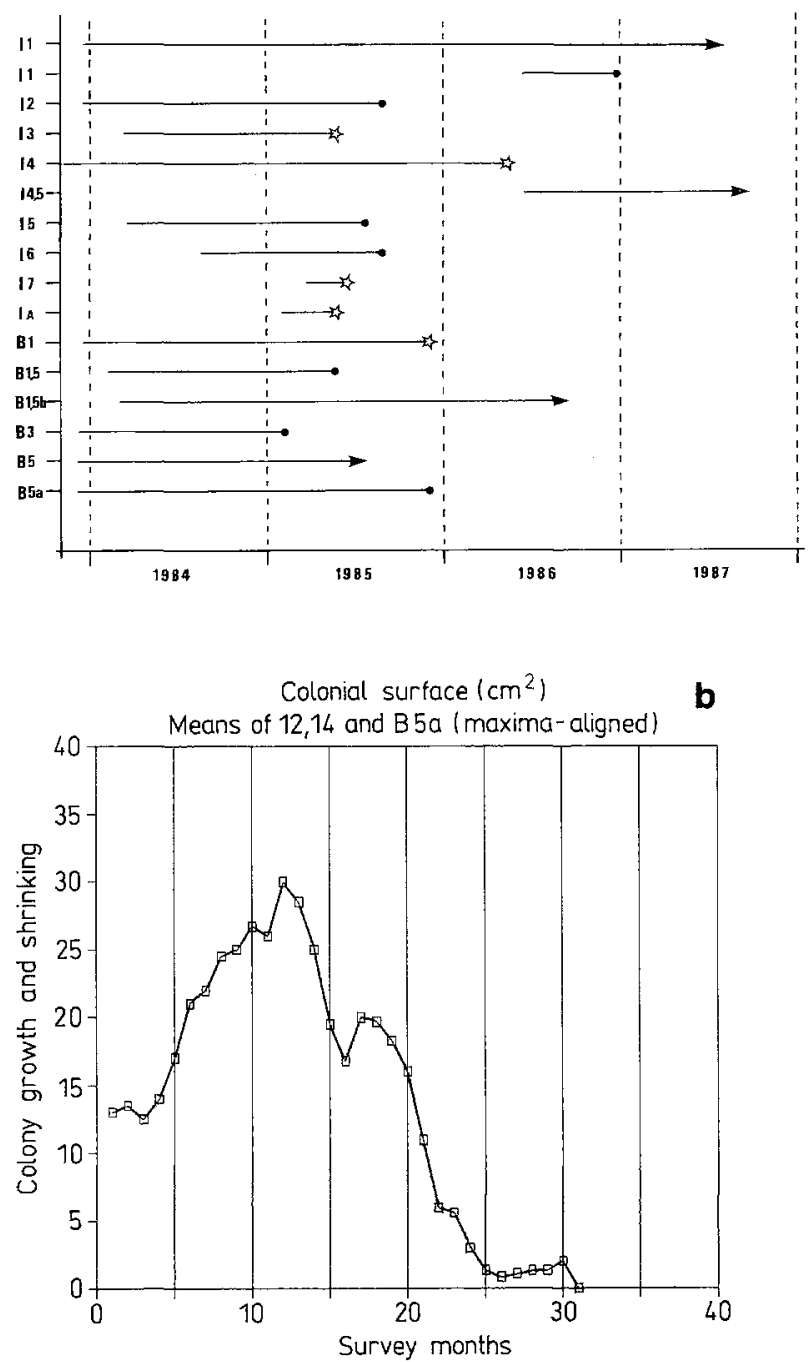

Fig. 1. a Polysyncraton lacazei: Sixteen colonial lifespans as assessed by a 4 year in-situ monitoring. Arrow: colony still healthy at survey end. Star: colony destroyed by catastrophic event. Black dot: colony death after period of shrinking. b $P$. laczei: phases in colonial life: growth, shrinking, disappearance (colonies I2, I4, B5a aligned on day of their maximum expansion, $y=$ three-colonymean of total clone surface). Extrapolation of left hand slope to $y=0$ (theoretical settlement of founder larva) indicates a lifespan of approximately 36 months 
(Fig. 1a) or surface area changes (Fig. 1b) the whole clone issued from the initially marked colony was treated as a unit.

Marked colonies/clones survived for between 4 months and 3,5 years after installation of the frames (see Fig. 1 a).

Causes of mortality were either catastrophic events, such as heavy storms, injury by passing sea urchins and the like (no predation observed!), or apparently endogenous factors ("aging"?). The latter phenomenon consisted of a progressive shrinking of the colony/clone with diminution of zooid numbers over several weeks until complete disappearance (Fig. 1 b). In these cases no external factors, either abiotic (temperature, turbulence ...) or biotic (competition, epibiosis, predation ...) could be related to the degeneration of the ascidians. Interestingly, in most instances clonemates formed by previous fission of a colony degenerated synchronously, even when the separation lay back several months.

5 of the 16 marked colonies were lost by catastrophic events (mostly storms that either destroyed the colonies or dislocated the marking frame).

7 colonies died "naturally" at the end of a typical degeneration phase. The remaining 4 colonies were in good condition when the monitoring ended.

Average survival time of these colonies was 17.6 months ( $\mathrm{sd}=10.3 \mathrm{mth}$ ). This value is only part of a colony's life span, because monitoring started at an unknown time after settlement of the founder larva. As colony size changes continuously by growth, colony fusion and division, it is virtually impossible to deduce the age of a colony from morphological features. Figure $1 \mathrm{~b}$, however, suggests some coherent pattern in the evolution of clone surface (sum of clonemate surfaces): growth phase, maximum expansion, shrinking, disappearance. If one completes mentally the growth slope in the left part of Fig. $1 \mathrm{~b}$ until reaching the X-axis (that is the extrapolated moment of larval settlement) one has to add about 5 months to the life of the colonies and comes up with a total average lifespan of about three years for these colonies. This estimate seems to be supported by colonies $\mathrm{B} 1.5 \mathrm{~b}$ and $\mathrm{I} 1$ that still proliferated after 29 and 42 months, respectively. A lifespan of 2-3 years for colonial ascidians is consistant with findings or estimates by Bak et al. (1981) and Millar (1971).

The one incontestable conclusion possible at this moment is that the average colonial lifespan of this Polysyncraton population undoubtedly exceeds 18 months.

\section{b) Epibionts (E)}

The test results can be summarized by the statement that for the vast majority of potential colonizers the colony surface of Polysyncraton lacazei seems to constitute a quite unsuitable substratum. The exceptions to this rule are: i) one kamptozoan and one diatom species that occurr occasionally even on actively filtrating colonies and ii) a rather heavy colonization of the inert surface of "resistance form" colonies.

\section{i) Active colonies}

-Optical screening: On active colonies only two epibiont species were ever found: One, a benthic diatom (Navicula sp.), occurred sporadically ( $<8 \%$ of the colonies). Usually, only single cells were present on the colonies. In the very few cases $(<1 \%$ of the specimens examined) that the diatoms were numerous enough to form patches, these were localized around the sipho openings.

The other epibiont was a kamptozoan, Loxocalyx sp. (probably L. pes: Prenant and Bobin 1956). Of all colonies examined $(\mathrm{n}=959) 21,2 \%(\mathrm{sd}=21,3 \%)$ bore mostly single Loxocalyx individuals $(<10$ individuals/ $\mathrm{cm}^{2}$ ), less than $1 \%$ exhibited a dense kamptozoan cover $\left(>500\right.$ individuals $/ \mathrm{cm}^{2}$ ). The distribution of Loxocalyx on the ascidian colonies seemed perfectly random.

Loxocalyx reaches a length of $0,3-0,8 \mathrm{~mm}$, its body is composed of an ovoid structure (the calyx) bearing 10 tentacles, and a stalk with, at its lower end, a threetoed foot provided with an adhesive-secreting gland (Fig. 2). These kamptozoans are solitary, reproduce sexually or by lateral budding at the calyx margin. They are attached reversably to their substratum and are able to move about by looper-like motions. Most kamptozoans, like Loxocalyx, are reported to live epibiotically (Cori 1936).

In the present case the association between Loxoca$l y x$ and Polysyncraton seems to be facultative for both partners: the ascidian can live very well without the kamptozoan (and in the majority of cases does), and the latter grows with equal ease on other filtrators: didemnids (Didemnum coriaceum, D. fulgens, D. maculosum, Trididemnum cereum, pers. obs.) and, probably, sponges (Cori, op.cit.). High specificity and special coadaptations seem to be absent.

Presence of Loxocalyx on Polysyncraton was highly irregular as indicated by the elevated standard deviation.

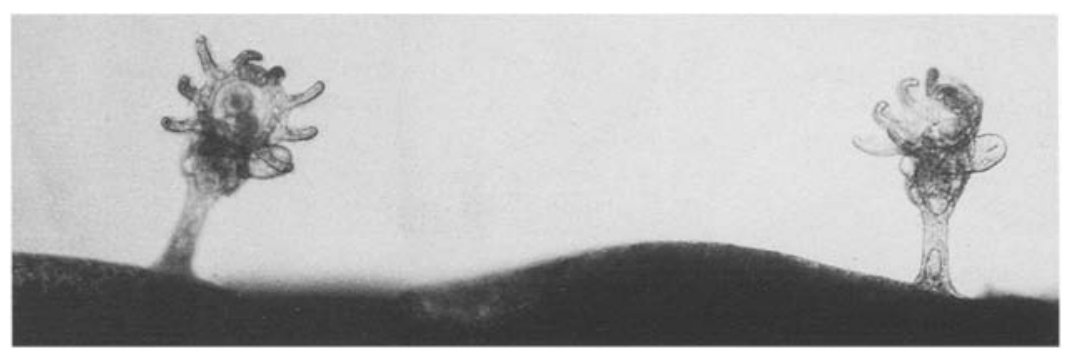

Fig. 2. Macrography of a Loxocalyx - individual on the rim of a Polysyncraton colony (photo: J. Lecomte, CNRS, Lab. Arago, Banyuls/mer) 
Table 1. Bacterial densities on different substrates as found in this study (swabbing) and by other authors (SEM)

\begin{tabular}{llc}
\hline Substrate & Ref. & $\begin{array}{l}\text { Calc. bact. density } \\
\left(\mathrm{cm}^{-2}\right)\end{array}$ \\
\hline $\begin{array}{l}\text { Sterile Cotton } \\
P . \text { lacazei }\end{array}$ & $\begin{array}{l}\text { (this work) } \\
\text { (this work) }\end{array}$ & \\
- active colony & & \\
- resistance form & & 250 \\
Glass & (this work) & 450 \\
$\quad$ immersed 2 wks) & & 19500 \\
Algae & Booth and Hoppe 1985 & $500000-3000000$ \\
Laminaria sp. & Mazure and Field 1980 & $10000-10000000$ \\
Aquatic Plants & Baker and Orr 1986 & $100000-10000000$ \\
Posidonia oceanica & Novak 1983 & $2500000-14000000$ \\
Bryozoa & Novak 1983 & $500000-15000000$ \\
\hline
\end{tabular}

Percentage of colonized colonies varied strongly between habitats and - within the same population - with time. Interestingly, at one monitoring site (3-10 $\mathrm{m}$ depth) not a single kamptozoan was found in 2 years $(n=246$ colonies). Even on one and the same colony Loxocalyx abundance was observed to oscillate temporally between 0 and $>100$ ind. $/ \mathrm{cm}^{2}$ (as estimated by underwater macrography of the monitored colonies), high epibiosis phases alternating with epibiont-free periods in the space of days or weeks. Possibly, the observed rather abrupt decrease of Loxocalyx numbers on previously heavily fouled colonies is an effect of a (induced?) defense (Wahl, unpublished work).

Neither environmental factors, nor ascidian reproductive cycle data showed any correlation with the fluctuations of Loxocalyx abundance.

- SEM-screening. On activly filtrating colonies no bacteria, cyanobacteria or other microepibionts could be detected. The colony surface is literally sterile (Fig. 3 a). - Swabbing. The axenic nature of the Polysyncraton sur- face was largely confirmed by the microbial swabbing test. Bacterial cell numbers on $P$. lacazei were less than in the sterile controls ("background noise"), about 80 times smaller than on a glass slide immersed for 23 weeks, and 40 to 60000 times lower than on some other biological substrata (Table 1).

\section{ii) Resistance form}

As in other colonial ascidians (Sabbadin 1973; Bak et al. 1981), Polysyncraton zooids are renewed periodically. During this process the thoraces are resorbed, filtration ceases, the sipho openings are sealed by a thick cuticle that covers the entire external surface of the colony and the whole organism exhibits a complete outer inactivity ("resistance form", possibly the same outer aspect corresponds to true resistance forms acquired to pass adverse periods; Millar 1971). Internally, a new generation of thoraces buds from the persisting abdomens (Turon 1988). When these former become functional, the exterior cuticle ruptures at one or several points and slowly peels off the colony surface.

Nothing is known about the duration of this rejuvenation process (our estimate is about one week) or the time span between two such events in a same colony, that is the life span of the zooids or, rather, thoraces.

When Polysyncraton passes through such a phase of outer inactivity the quality of the surface seems to change drastically, apparently becoming much more suitable for colonization. In fact, the resitance form gets fouled easily and often bears a quite mature epibiotic assemblage composed of bacteria, cyanobacteria, diatoms, protozoans, algae and numerous motile grazers (Fig. 3b). A quite similar phenomenon has been mentioned for "dead fragments" of otherwise unfouled tunic of Botryllus schlosseri (colonial ascidian; Rinkevich \& Weissmann 1987). When the Polysyncraton cuticle is re-
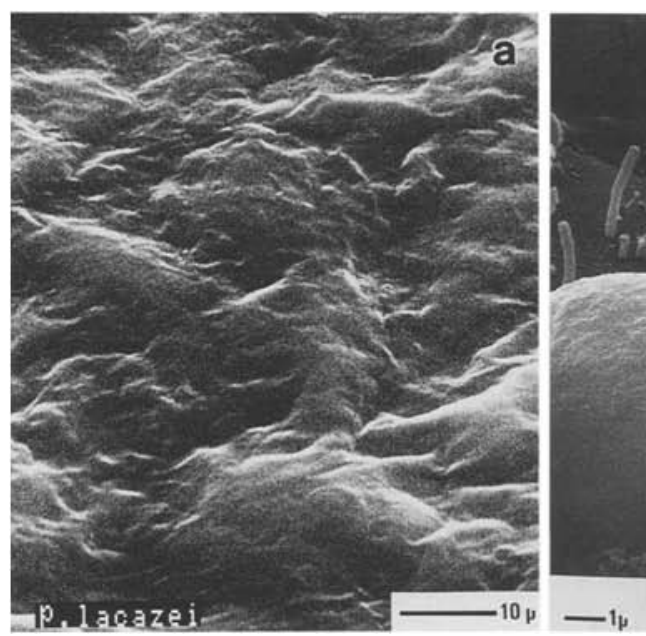

Fig. 3. a Typical SEM-micrography of an active colony's surface: the cuticle is perfectly clean, even axenic; $\mathbf{b}$ The cuticle of a resistance form colony is quickly (ca $1 \mathrm{wk}$ ) colonized by cyanobacteria
(1) and bacteria (2): slime film; c Older (ca 3 wks) resistance form cuticle (1), heavily fouled and beginning to peel off (moult). (2) = new, epibiont-free surface of active form 
jected by the kind of moult described above at the moment of colony reactivation, the newly emerging surface is as sterile and epibiont poor as before (Fig. $3 \mathrm{c}$ ). Yet, this case of Polysyncraton - fouling should be classed as an 'exception from the rule', the resistance form being a rather rare biological state in this ascidian $(<15 \%$ year-round average: Turon 1988).

\section{Conclusion and presentation of an antifouling potential index}

In the light of the biology of $P$. lacazei the results obtained are not entirely surprising: like other ascidians, Polysyncraton is a filtrator, feeding essentially on small phytoplankton (Fiala-Medioni 1978). Filtering units are the tiny zooids (1-2 mm body length) that, sitting side by side within the common tunic, compose the flat, en- crusting colony. The ingestion sipho of each individual opens through the colony surface which therefore appears closely perforated by thousands of small holes (ca. $250 \mu \mathrm{m}$ diam., up to several hundred per $\mathrm{cm}^{2}$, Fig. 4). Consequently, to guarentee efficient filtration throughout the year, epibiosis on the entire colony surface must be kept at a minimum. Especially, macroepibionts can severely alter filtering conditions by depleting incoming water (if they are suspension feeders, too) and/or by altering current patterns at the colony surface (Okamura 1988). The effect of any particular case of epibiosis on Polysyncraton is a function of colonizing density and the epibiont's biology and size (Fig. 4b).

Seemingly, an occasional colonization by Loxocalyx (body length $300-800 \mu \mathrm{m}$ ) is all $P$. lacazei may tolerate. Even in this case, for an individual colony Loxocalyx epibiosis seems of short duration (ca. 2-4 weeks), especially if the cover becomes dense. The occasionally
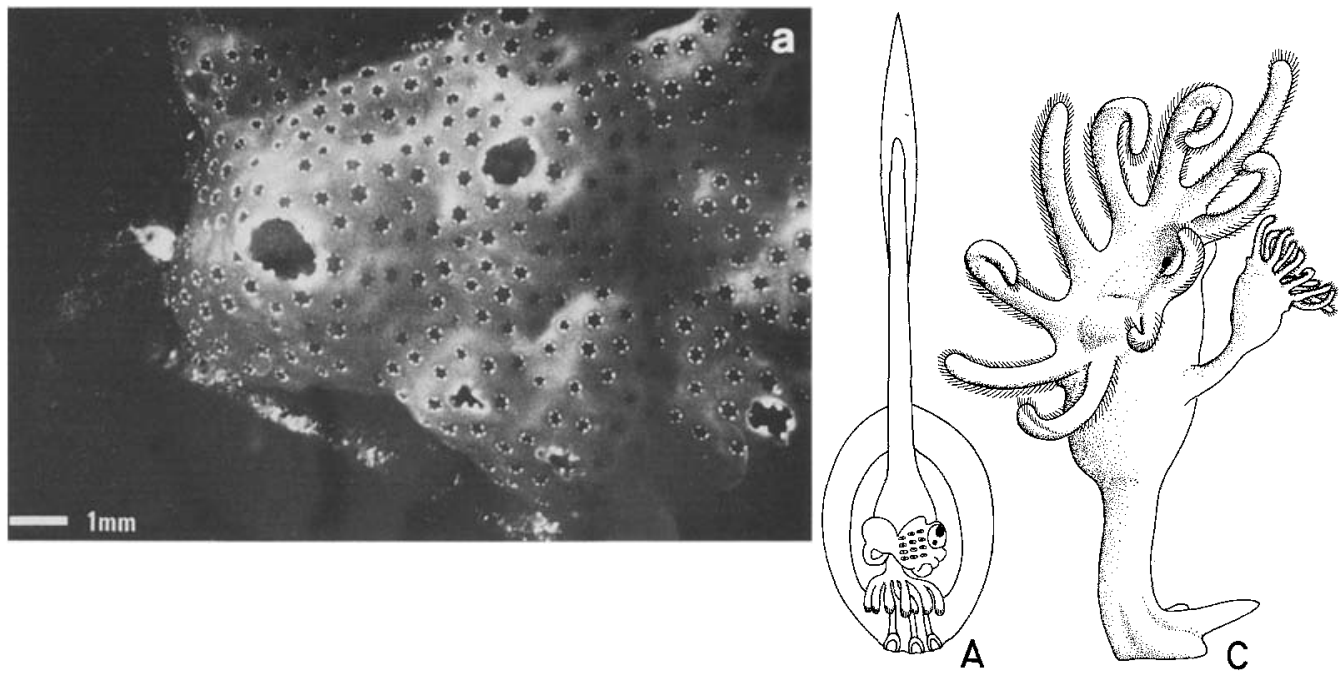

b1
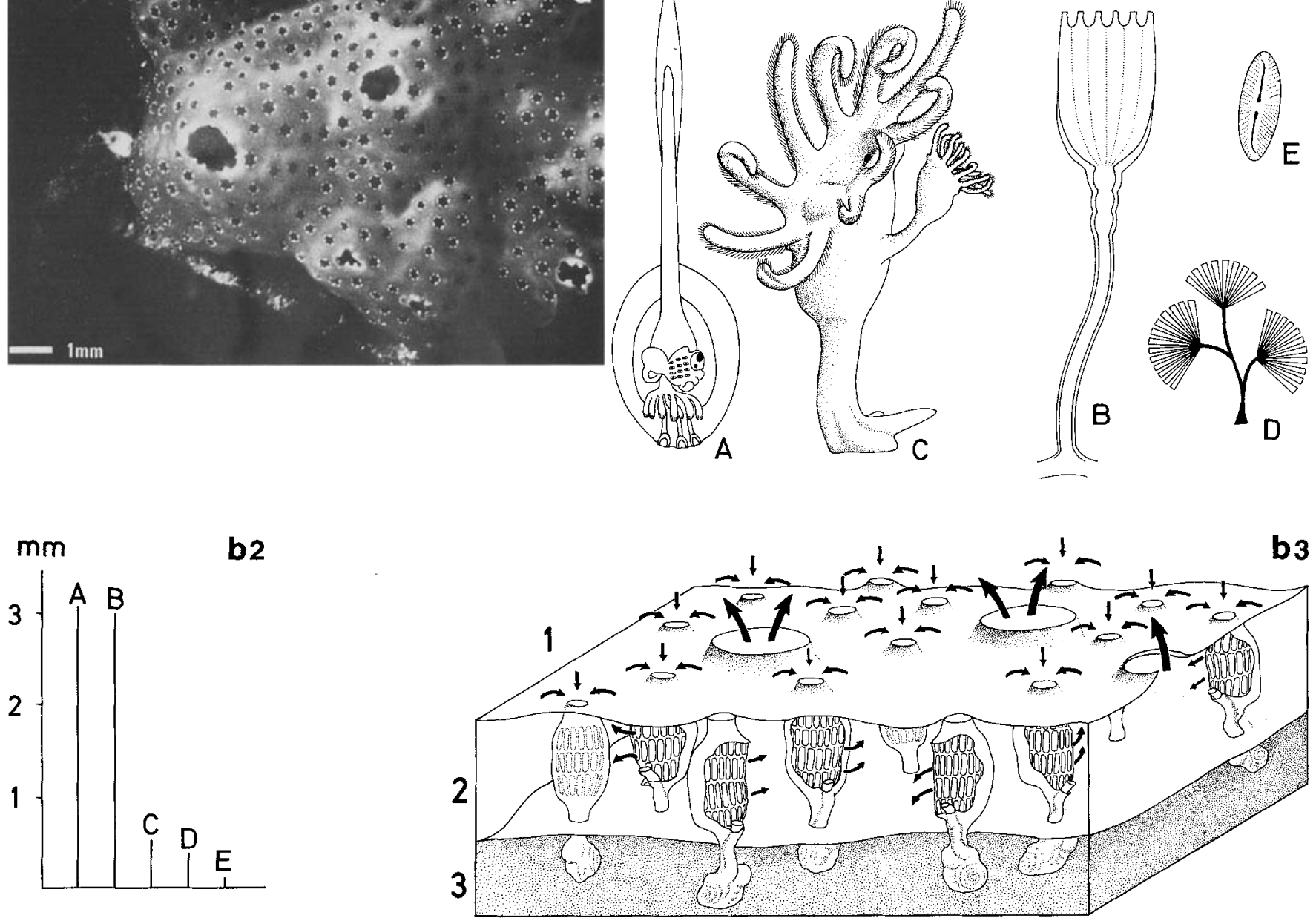

Fig. 4. a Underwater macrography of active Polysyncraton colony showing individual ingestion sipho openings (diameter ca $0,25 \mathrm{~mm}$ ) and common cloacal sipho openings (diameter ca $1 \mathrm{~mm}$ ). b Schematic drawing of $P$. lacazei colony and selected potential colonizer species to illustrate size relations and possible effects of epibiosis (b2 and $\mathrm{b} 3$ at the same scale) (drawings by $\mathrm{H}$. Sönnichsen). b1. Examples of potential colonizers: $\mathrm{A}=$ ascidian larva, $\mathrm{B}=$ Campanu- laria sp. (hydrozoon), $\mathrm{C}=$ Loxocalyx sp. (kamptozoon), $\mathrm{D}=$ Licmophora sp. (diatom), $\mathrm{E}=$ Navicula sp. (diatom). b2. Absolute body lengths of colonizers in b1. b3. Block diagram of $P$. lacazei colony: $1=$ colonial surface with siphonal openings, $2=$ thorax region with common cloacal canal system leading to exhalant sipho, $3=$ basal region with abdomens 
observed abrupt disappearance of the epibionts may be due either to an inherent biological cycle of the kamptozoan or to an induced defence (chemical or mechanical) of the ascidian.

Microepibionts (diatoms, cyanobacteria, bacteria ...) could be deleterious in other ways: chemical attack of the colony surface by slime film metabolism, promotion of further fouling by creation of holdfasts or nutrientrich microenvironments or of an insulating layer between newcomers and ascidian toxins, etc. (Wahl 1989). For these reasons (and maybe others still), even if they would not hinder significantly filtration flow, microepibionts are not tolerated either.

Consequently, fouling to any extent on $P$. lacazei is only tolerated when such vital processes as filtration are temporarily shut off (resistance form). This phenomenon is forcibly transitory.

In order to decide whether this near-total absence of epibionts on Polysyncraton is due to external factors such as high-stress habitat, absence of colonizers, etc. or attributable to properties of the basibiont (e.g. antifouling defenses), a closer look must be taken at the parameters characterizing the "epibiotic situation' of a given organism. Quite obviously, the intensity of fouling on a given substratum depends - apart from the substratum's surface properties - on the number of local colonizer species (CP), the local fouling rate (FP) and the exposure time (A) of the substratum. The actual number of epibiont species (E) on the surface under investigation relative to $\mathrm{CP}$ illustrates the degree of selectivity of the substratum vis-à-vis fouling. These four parameters describe the epibiotic situation of a given potential basibiont and may tentatively be defined as follows:

$-\mathrm{CP}$ : number of local fouling species settling during the lifetime of the organism/substratum under investigation, assessible by exposure of fouling panels or desactivated surfaces of the organism studied (e.g. carapaces of freeze-killed crabs). CP should be composed solely of such species whose settling forms are sensibly smaller than the potential basibiont in question.

-FP: time required for a reference substratum to become fouled in the studied basibiont's habitat and during the season(s) this latter lives. While the beginning of the fouling process is easily defined by the instant of first contact between a new surface and seawater, its end is open. The end of a reference period must be fixed arbitrarily, e.g. arrival of the first metazoan larvae. Thus an approximate notion of the biological activity of the local waters with respect to fouling may be obtained: the shorter FP, the higher the local fouling rate.

$-\mathrm{A}$ : period through which an organism is exposed to colonization. For short-lived $(<1 \mathrm{yr})$ species A will be identical to lifespan. The maximum value for A should be 1 (yr), because - given the typical planktonic cycles - perennial species will not be exposed to significantly higher CPs. Surface renewais such as mucus secretion and sloughing should not be used to define A, even if they seem to diminish the longevity of the organism/ environment interface. Frequently, these phenomena are to be considered as antifouling defense adaptations themselves (Filion - Myklebust and Norton 1981, Barthel and Wolfrath 1989).

$-E$ : number of fouling species occurring regularly on the organism studied. In order to assess this parameter numerous basibiont individuals covering different age classes, habitats and seasons must be screened. A 'regularity" threshold, e.g. presence on $>10 \%$ of basibiont individuals, must be fixed to compensate for the atypical heavy fouling of certain specimens weakened by physical stress, nutrient lack, parasitism, old age, etc.

Once these four parameters are known we may combine them mathematically to define an index ( $\mathrm{AFP}=$ antifouling potential index) which on the one hand yields integrated information about a given epibiotic situation and, on the other hand, will help evaluate the probability of the presence of antifouling defenses in the basibiont studied. This index should be understood as a first throw and is primarily intended to ignite the discussion:

$\mathrm{AFP}=(1-\mathrm{E} / \mathrm{CP}) \times \mathrm{A} /(\mathrm{FP}+\mathrm{A})$

where $\mathrm{E} / \mathrm{CP}$ is the fraction of the locally present colonizer species actually settling on the substratum. Inversely, 1-E/CP represents the fraction of the colonizer pool

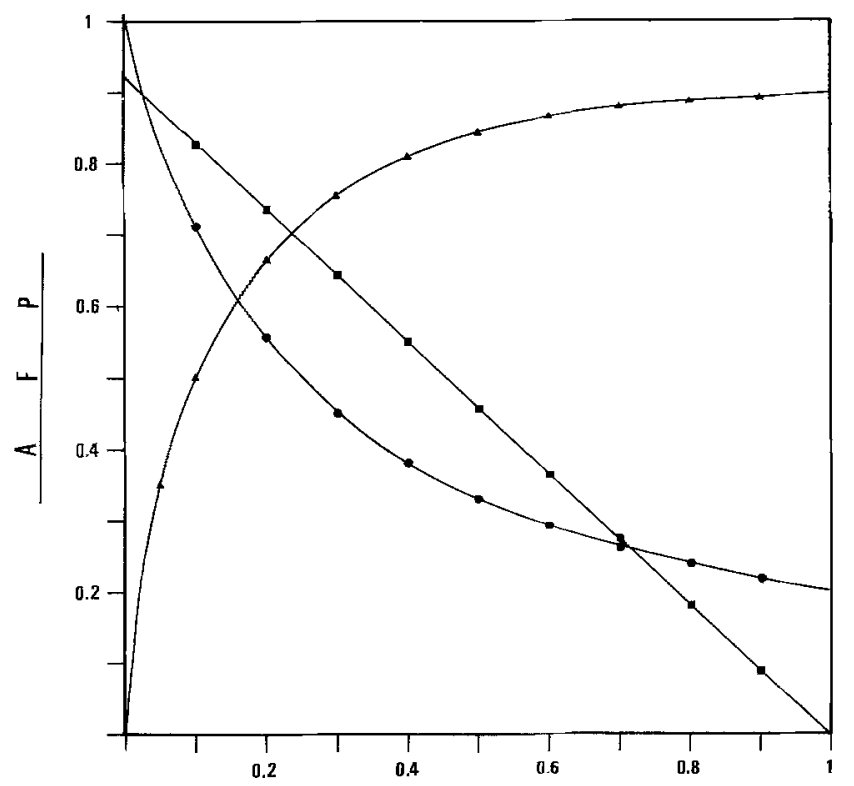

Fig. 5. Modulating influence of the different epibiotic parameters on the $A F P$-index with remaining parameters kept constant (theoretical graph based on AFP-formula proposed in this paper): Squares: $\mathrm{x}=$ Epibiotic status $(\mathrm{E} / \mathrm{CP})$. Obviously, the more a given organism is fouled, the less-probable it is that it harbors potent antifouling defenses: AFP decreases linearly. $(A=1 \mathrm{yr}, F P=$ $1 \mathrm{mth}, \mathrm{x}$-axis dimensionless). Triangles: $\mathrm{x}=$ Exposure time $(\mathrm{A})$. For a given epibiotic status (E/CP), long-lived species are attributed a higher AFP than ephemeric ones, the surfaces of the former facing colonization pressure for a longer period. The increase of AFP with lifespan is proportional to the difference between FP and $A$ (with $F P<A) .(E / C P=0.01, F P=1 \mathrm{mth}$, unit of $x$-axis is years). Dots: $\mathrm{x}=$ Fouling period (FP). With diminishing biological activity of the waters (increasing FP) it gets easier to stay epibiontfree, especially for short-lived organisms: AFP decreases. $(\mathrm{E} / \mathrm{CP}=$ $0.01, \mathrm{~A}=3 \mathrm{mth}$, unit of $\mathrm{x}$-axis is years) 
(CP) not found on the basibiont - often as a consequence of antifouling defenses. The second expression A//FP + A) modulates the impact of the first by introducing longevity relative to the local fouling period. Thus we take account of the fact that - in the absence of defenses at least - fouling is proportional to exposure time (longevity) relative to local fouling activity.

As to the index itself, AFP (ranging between 0 and 1) was conceived with the intention to extract from the four epibiotic parameters information about the antifouling defense potential to be expected in a given sessile species as deduceable from its epibiotic situation. The underlying idea is that at least in energy limited environments - and accepting the hypothesis that defense is costly - not more resources are invested into defense than required by a species' biology versus external fouling pressure (Wabl 1989). The index is designed to express the 'effort' necessary for a given basibiont with a specific A to maintain a given degree of fouling (E) in a given environment (CP, FP). For example, a little fouled (low E), perennial (high A) organism living in a tropical marine habitat (high $\mathrm{CP}$, short FP) will be attributed a high AFP and presumably exhibits efficient antifouling defenses, whereas a short-lived, little fouled boreal species (low A, low E, low CP, longer FP) may get along with a significantly lower level of antifouling defenses as indicated by a smaller AFP (Fig. 5). Note that the notion of 'defense' is used here in its broadest sense, comprising for instance physical, mechanical, chemical, extrinsic and associational protective adaptations (Pfister and Hay 1988, Wahl 1989).

In the case of Polysyncraton only $\mathrm{E}$ and $\mathrm{A}$ have been quantified. But in view of the rapid and species-rich fouling of neighboring substrata (rock surface, fouling-tolerant species) we may expect a high AFP (low E, high $\mathrm{A}$, high $\mathrm{CP}$, short FP) and consequently predict the existance of efficient antifouling defenses. Naturally, AFP may be determined for other, partial, aspects of the fouling problem: for example, forecasting antibacterial defenses by using only bacteria-relevant parameters in the formula (actual bacterial epibionts: $\mathrm{E}(\mathrm{b})$, potential bacterial colonizers: $\mathrm{CP}(\mathrm{b})$, etc.).

Finally, AFP may find an application in the testing and subsequent classification of the performance of new antifouling paints: $\mathrm{CP}=$ fouling species on controls, $\mathrm{E}=$ colonizers on a given test panel, $\mathrm{A}=$ duration of test, FP as usual. In this case one further parameter should contribute to the qualification of the paint: its toxic environmental impact determined by in-vitro experiments.

Obviously, this index is a compromise between ecological precision and practicability. Thus, diversity would represent a more adequate measure for $E$ and $\mathrm{CP}$ than species number. But in most instances obtaining these former data would demand a disproportionally high amount of work. For the time being, not enough data on a variety of epibiotic situations are available to test whether AFP is quantifiable, and only further work on epibiosis and critical comments from other workers in the field will show whether the index proves of general usefullness.
Concluding, this index was conceived to serve two main purposes:

1-comparison of different cases of epibiosis (or fouling) 2 -forecast of absence, presence, strength of antifouling defenses as deduccable from a particular epibiotic situation (in energy limited habitats). The first application will be unproblematic if well defined and, whenever possible, standardized techniques for the assessment of $\mathrm{CP}$ and FP are employed. The second will work out only if the current hypothesis on resource allocation "on demand" (Coley et al. 1985; Rhoades 1985; Coley 1986; Larsson et al. 1986; Bazzaz et al. 1987; Nitao and Zangerl 1987; Van Alstyne 1988; Fagerström 1989) holds true. Maybe AFP proves a suitable tool for testing this hypothesis for one particular situation: marine epibiosis.

Acknowledgements. We are grateful to Dr. I. Kronberg (Kiel) for help with the mathematical conception of AFP and for critically reading the manuscript.

\section{References}

Bak RPA, Sybesma J, Duyl FC van (1981) The Ecology of the Tropical Compound Ascidian Trididemnum solidum II. Abundance, Growth Surv Mar Ecol Progr Ser 6, 43-52

Baker JH, Orr DR (1986) Distribution of Epiphytic Bacteria on Freshwater Plants. J Ecol 74:155-165

Barthel, D., Wolfrath B (1989) Tissue Sloughing in the Sponge Halichondria panicea: a Fouling Organism Prevents Being Fouling. Oecologia 78: 357-360

Bazzaz FA, Chiariello NR, Coley PD, Pitelka LF (1987) Allocating Resources to Reproduction and Defense. Bio Science 37:58-67

Booth WE, Hoppe H-G (1985) Epiphyte Bacterial Activity on Different Macroalgal Species Determined by Tritiated Thymidine Incorporation. Bot Mar 27:47-56

Coley PD (1986) Costs and Benefits of Defense by Tannins in a Neotropical Tree. Oecologia 70:238-241

Coley PD, Bryant JP, Chapin FS III (1985) Resource Availability and Plant Antiherbivore Defense. Science 230:895-899

Cori CI (1936) Kamptozoa In: Brouns HG (ed) 'Klassen und Ordnungen des Tierreiches' Band 4 (II, 4). Akad Verlagsges Leipzig, 1936, pp 1-119

Fagerström T (1989) Antiherbivory Chemical Defense in Plants: A Note on the Concept of Cost. Am Nat 133 (2):281-287

Fiala-Medioni A (1978) Nutrition d'invertebres benthiques filtreurs. These Docteur d'Etat, Paris VI, 1978

Filion-Myklebust C, Norton TA (1981) Epidermis Shedding in the Brown Seaweed Ascophyllum nodosum (L.) Le Jolis, and its Ecological Significance. Mar Biol Lett 2:45-51

Larsson S, Wiren A, Lundgren L, Ericsson T (1986) Effects of Light and Nutrient Stress on Leaf Phenolic Chemistry in Salix dasyclados and Susceptibility to Galerucella lineola (Coleoptera). Oikos 47:205-210

Mazure HGF, Field JG (1980) Density and Ecological Importance of Bacteria on Kelp Fronds in an Upwelling Region. J Exp Mar Biol Ecol 43:176-182

Millar RH (1971) The Biology of Ascidians. Adv Mar Biol 9:1-100

Monniot C (1961) Un connex ecologique: Les Microcosmus de Banyuls/mer. These Doctorat 3e Cycle, Univ Paris, 1971, p 211

Nitao JK, Zangerl AR (1987) Floral Development and Chemical Defense Allocation in Wild Parsnip (Pastinaca sativa). Ecology $68:$ (3) $521-529$

Novak R (1984) A Study in Ultra-Ecology: Microorganisms on the Seagrass Posidonia Oceanica (L.) Delile. Mar Ecol 5:(2) $143-190$ 
Okamura B (1988) The Influence of Neighbors on the Feeding of an Epifaunal Bryozoan. J Exp Mar Biol Ecol 120:105-123

Pfister CA, Hay ME (1988) Associational Plant Refuges: Convergent Patterns in Marine and Terrestrial Communities Result from Differing Mechanisms. Oecologia 77:118-129

Prenant M, Bobin G (1956) Faune de France. 60. Bryozoaires. Premiere partie: Entoproctes, Phylactolemes, Ctenostomes. Faune de France, Editions P. Lechevalier, Paris, 1956, p 398

Rhoades DF (1985) Offensive-Defensive Interactions Between Herbivores and Plants: Their Relevance in Herbivore Population Dynamics and Ecological Theory. Am Nat 125:205-238

Rinkevich B, Weissman IL (1987) The Fate of Botryllus (Ascidia- cea) Larvae Cosettled with Parental Colonies: Beneficial or Deleterious Consequences? Biol Bull 173:474-488

Sabbadin A (1973) Recherches experimentales sur l'ascidie coloniale Botryllus schlosseri. Bull Soc Zool France 98:(3) 417-434

Turon X (1988) The Ascidians of Tossa de Mar (NE Spain). II. Biological Cycles of the Colonial Species. Cah Biol Mar 29:407-418

Van Alstyne KL (1988) Herbivore Grazing Increases Polyphenolic Defenses in the Intertidal Brown Alga Fucus distichus. Ecology $69:$ (3) $655-663$

Wahl M (1989) Marine Epibiosis. I. Fouling and Antifouling: Some Basic Aspects. Mar Ecol Progr Ser 58:175-189 